\title{
Prevalence and predictors of MRSA carriage among employees in a non-outbreak setting: a cross-sectional study in an acute care hospital
}

Melanie Schubert ${ }^{1 *}$ (D), Daniel Kämpf ${ }^{1}$, Lutz Jatzwauk ${ }^{2}$, Franziska Kynast ${ }^{1}$, Annette Stein ${ }^{3}$, Ruth Strasser ${ }^{4}$, Madeleine Dulon $^{5}$, Albert Nienhaus ${ }^{5,6}$ and Andreas Seidler ${ }^{1}$

\begin{abstract}
Background: Health care workers have an increased risk of being infected with Methicillin-resistant Staphylococcus aureus (MRSA), though little information is available about how prevalent (dormant) MRSA colonization is among health care workers. The aim of this study was to estimate the prevalence and predictors of MRSA carriage in a non-outbreak setting in a university hospital in Germany.

Methods: The entire staff of a university hospital heart center for cardiologic maximum medical care and cardiac surgery were invited to participate in a cross-sectional study $(N=575)$. The sampled population included health care workers as well as employees with no close patient contact.

A questionnaire concerning personal and occupational risk factors as well as lifestyle and demographic factors was applied and nasal swabs were taken. In total 180 persons (31.3\%) participated in the study.

Results: The majority of study participants had close contact to patients at work ( $n=149,82.8 \%)$. Thereof, about one-third had contact to MRSA-patients $(n=53,35.6 \%)$, and most reported wearing protective clothing $(n=44,83$. $0 \%)$. None of the administrative staff tested positive for MRSA and only one in 149 persons $(0.7 \%, \mathrm{Cl} 0.00-0.02)$ with close patient contact carried MRSA (strain CC1-MRSA-M). This person had close contact to patients with MRSA, less than 1 year of work experience, and had been treated with antibiotics within the last 12 months.
\end{abstract}

Conclusion: The results of our study suggest low point prevalence rates of MRSA colonization in health care workers in a non-outbreak setting.

Keywords: Health care workers, MRSA prevalence, Non-outbreak setting, Risk factors, MRSA strain

\section{Background}

Staphylococcus aureus is a ubiquitous gram-positive bacterium that most commonly colonizes the human nasal vestibule and skin. The methicillin-resistant form Methicillin-resistant Staphylococcus aureus, abbreviated MRSA - is an important cause of nosocomial infections worldwide [1]. Though a general decrease in MRSA has been observed by the European Centre for Disease Prevention and Control for the European Union [2], MRSA

\footnotetext{
* Correspondence: Melanie.Schubert@tu-dresden.de

'Institute and Policlinic of Occupational and Social Medicine, Medical Faculty Carl Gustav Carus, Technische Universität Dresden, Dresden, Germany Full list of author information is available at the end of the article
}

still accounts for over $40 \%$ of healthcare-associated infections in the European Union [3]. Health care workers (HCWs) may serve as a reservoir and vehicle of spreading MRSA [4, 5]. A systematic review assessing 191 MRSA outbreaks found that HCWs were the source in 11 of 191 outbreaks, and asymptomatic carriers were the source in three of the outbreaks. Moreover, transmission of MRSA to household members is also likely to occur [6-8]. Routine screening of $\mathrm{HCW}$ staff is controversial, although it has been shown that screening could help decrease MRSA infection rates $[9,10]$.

Little is known about the prevalence of MRSA carriage in non-outbreak situations. In a systematic review

(c) The Author(s). 2019 Open Access This article is distributed under the terms of the Creative Commons Attribution 4.0 International License (http://creativecommons.org/licenses/by/4.0/), which permits unrestricted use, distribution, and 
including studies from non-outbreak settings in Europe and the US, the pooled prevalence of MRSA carriage in HCWs was $1.8 \%$ (95\% CI 1.34-2.50), and increased to $4.4 \%$ (95\% CI 3.98-4.88) when one study from the Netherlands was excluded from the analysis [11]. This latter prevalence is similar to the results of a recent study performed in a non-outbreak setting in nine German acute care hospitals which observed MRSA carriage prevalence rates for medical staff of 4.6\% [12].

MRSA carriage rates have been shown to be highest in nursing staff. The aforementioned systematic review also found that nurses had an increased risk of 1.72 (95\% CI 1.07-2.77) when compared with medical staff, and a risk of 2.58 (95\% CI 1.83-3.66) when compared with other healthcare staff [11]. Also, in the recent German study by Sassmannshausen and colleagues [12] mentioned above, nurses had a higher MRSA carriage prevalence compared to physicians (5.6\% versus $1.2 \%$ ). Ibarra and colleagues found similar risks for physicians (13\%), nurses (12\%), and other healthcare professionals in the US [13]. Risk factors for MRSA carriage in HCW are a known history of MRSA infection or colonization, direct contact with patients with MRSA infections, recent hospitalization or emergency department visit, and recent antibiotic use [13-15]. Other risk factors are chronic skin disease, poor hygiene practices, and working in countries with endemic MRSA. Nurses with occupational skin disease have been shown to have a higher risk for MRSA colonization [16].

MRSA carriage might be chronic or intermittent, where persons are colonized for a short time period. One form of intermittent carriage is the transient carriage, where MRSA isolated after work is gone before next day's duty [17]. MRSA eradication is usually successful in the majority of HCWs (88\%) [15], and successful decolonization (with mupirocin) has been shown in $94 \%$ of cases 1 week after treatment [10]. About 5\% of MRSA colonized HCWs develop clinical infections [15] which may progress into serious disease or have negative consequences at work $[18,19]$. In Germany, about 50 potentially occupationally related cases involving Methicillin-resistant Staphylococcus aureus (MRSA) were reported per year in the last 5 years [20]. However, most of these cases concerned carriage of MRSA, which is not considered an occupational disease according to German regulations.

The present study aimed to describe the prevalence of MRSA carriage in a German acute care hospital and to identify risk factors associated with colonization. Results should provide a basis for improved workplace risk assessment identifying opportunities to prevent infections.

\section{Methods}

The study was conducted from July 2014 to May 2015. All employees $(N=575)$ of the heart center ("Herzzentrum Dresden $\mathrm{GmbH}^{\prime \prime}$, the specialized cardiology care and cardiac surgery center of the Technische Universität Dresden's teaching hospital, were invited to participate. An anonymous invitation, including study information, a questionnaire and informed consent, was sent with the monthly pay slip to each employee. The study team also presented the study with public talks at the center. This was done to inform the employees about the study and to give employees the opportunity to ask questions. For study participation, employees were asked to sign the informed consent and complete the questionnaire. The questionnaire included standard questions on personal characteristics and work, as well as questions concerning occupational and personal risk factors for MRSA. MRSA risk factors considered were predominately derived from a review by Albrich and Harbarth [15], a questionnaire used by the German Social Accident Insurance Institution for the health and welfare services (Berufsgenossenschaft für Gesundheitsdienst und Wohlfahrtspflege - BGW) for staff in nursing homes [21], and a literature search.

For sampling, the study team was on-site at the Herzzentrum Dresden for 2 days. Participants were invited to the examination room provided by the center. Initially, the informed consent and the completed questionnaire were collected and participants had the opportunity to ask questions. Then, samples were collected by a trained member of the study team using a swab from the anterior nares, which are the main reservoir for MRSA [11]. Employees had the choice to either participate anonymously or to receive feedback concerning the findings of their MRSA-analysis (either via post or by collecting the result in person at our policlinic).

All nasal swab samples were analyzed at the Institute for Medical Microbiology and Hygiene, Medical Faculty Carl Gustav Carus of the Technische Universität Dresden according to the quality guidelines of the laboratory. Antibiogram-resistogram typing with VITEK 2 and a PBP2a-Culture Colony Test (Alere Technologies GmbH) was done for positive MRSA samples. Moreover, MRSA-positive samples were genotyped using a "S. aureus Genotyping Kit 2.0" (Alere Technologies GmbH).

Descriptive statistics are shown for all data. Due to low sample size no statistical testing was performed. However, we included 95\% confidence intervals for MRSA colonization applying the "Rule of Three" [22]. Information for mean age of all employees and percentage of women working at the Herzzentrum Dresden was provided from the office of human resources. The mean age was 40.5 years, and $72 \%$ of employees were women.

In total, 180 employees participated in the study, resulting in a response of $31.3 \%$. Only three persons participated anonymously in the study; the majority of participants received the feedback via post $(n=171)$. Six participants collected the results from the study team. 


\section{Results}

Descriptive statistics for personal characteristics, as well as work-related and private risk factors for MRSA are displayed in Table 1 . In short, predominately women participated in the study (68.9\%). The majority of participants was between 40 and 49 (31.1\%) and 30-39 (24.4\%) years old, lived in a partnership (75.0\%), worked as a nurse (55.6\%), had a university entrance diploma (52.2\%) and 11-20 years of professional experience (41.1\%).

About one third $(n=53)$ have had contact to MRSA patients within the last 4 weeks. A similar proportion of participants $(n=58)$ reported not knowing whether they had contact or not. Of the employees reporting contact with MRSA patients, $83 \%$ of participants reported wearing protective clothing and about $80 \%$ of these persons reported wearing a surgical face mask, disposable gloves, and a lab coat. Three persons reported that they had occasional contact without protective cloths and another six persons did not answer the question.

Only three participants had contact to MRSA carriers at home. Nine persons were caring for relatives and 22 had contact to persons in need for care within the last 4 weeks. About half of participants had contact to pets $(n=89)$ and only a few to farmed animals $(n=9)$.

Four participants had MRSA in the past. Chronic skin disease and chronic respiratory disease were reported by about $10 \%$ each. Few participants suffered from diabetes mellitus (doctor's diagnosis: $n=3$, own diagnosis: $n=1$ ). About one third used antibiotics within the last 12 months $(n=57)$ and 16 participants had a hospital stay within the last 12 months.

None of administrative staff tested positive for MRSA. One of 149 persons with close patient contact carried MRSA (CI 0.00-0.02). This person worked on a normal ward (occupation: "others") and had less than a year of work experience. This participant had close contact to MRSA patients within the last 4 weeks and reported wearing protective clothing (surgical face mask, disposable gloves and lab coat) at all times. Furthermore, the participant was not aware of having contact to MRSA carriers away from work, did not care for relatives, and had no contact to persons in need for care within the last 4 weeks. The positively-tested participant did not work in the ambulant sector outside of the heart center and had neither contact to pets nor to farm animals. The participant had no chronic disease, but was treated with antibiotics within the last 12 months.

Genotyping revealed the strain CC1-MRSA-IV (WA MRSA - 1/57). Spa types associated with this strain are $\mathrm{t} 127, \mathrm{t} 386, \mathrm{t} 590, \mathrm{t} 922, \mathrm{t} 2601$. The isolate was mecA positive and PVL negative. The sample tested positive for the leukotoxin gamma-hemolysin. Gene virulence factors were enterotoxin $\mathrm{H}$ (she), hemolysin gamma/eukocidin component B (lukF), hemolysin gamma/eucocidin component C (lukS), hemolysin gamma/eukocidin component C, allele from ST22 and ST45 (lukS ST22+ ST45), hemolysin gamma component A (hlgA), leukocidin component D $(l u k D)$, leukocidin component $\mathrm{E}$ (lukE), staphylokinase (sak) and staphylococcal complement inhibitor (scn). The sample tested negative for Panton-Valentine leukocidin F component (lukF-PV) and Panton-Valentine leukocidin $\mathrm{S}$ component (lukS-PV).

The isolate was multi-drug resistant: Penicillinase (beta-lactamase gene, blaZ), MLS-antibiotics (rRNA metyltransferase associated with macroscelide/ lincosamide resistance, $\operatorname{crm}(C)$ ), aminoglycosides (aminoglycoside phosphotransferase (neo-/kanamycin), aphA3) and miscellaneous genes (streptothricin acetyltransferase, sat; tetracycline efflux protein, tet $(K)$ and chloramphenicol/ florfenicol exporter, texA).

\section{Discussion}

Our results suggest a low prevalence of MRSA in HCWs of less than 1\% ( 1 in $149 \mathrm{HCW}$ ). The observed MRSA carriage prevalence is lower than those reported by most other study groups of HCWs in German acute care hospitals, such as $4.6 \%$ [12], 5.3\% [23], 4.0\% [24], 3.2 and $2.8 \%$ [25]. This observation suggests a possible decline in MRSA carriage among HCWs in Germany. According to hygiene regulations at the heart center, workers with infectious diseases are prohibited from working with patients if a transmission of disease cannot be ruled out. On admission to the acute care hospital, patients are screened for MRSA (and 4 MRGN) if they have a history of MRSA, have chronic wounds, are on dialysis, or were transferred from other hospitals and rehabilitation centers. Patients with MRSA are isolated in single rooms. HCWs must wear gloves, a coat and a face mask when having direct contact with patients screening positive for MRSA. Successful decolonization of a patient is confirmed by three negative nose smears and one negative throat smear at least 3 days after antiseptic treatment. There were no MRSA outbreaks in the last 10 years at the hospital. A general decrease in MRSA has been observed by the European Centre for Disease Prevention and Control for the European Union [2]. Furthermore, well qualified and sufficient hygiene personnel are essential for preventing nosocomial infections. In Saxony, the number and qualification of hygienists in health facilities was legally determined in 2012 [26]. Thus, the low observed prevalence of MRSA might have resulted from sufficient hygiene staff education and compliance to hygiene measures [27].

The MRSA-colonized person worked on a normal ward (occupation: "others") and had less than a year of work experience. The participant had close contact to patients with MRSA within the last 4 weeks but reported 
Table 1 Descriptive statistics

\begin{tabular}{|c|c|c|}
\hline & Number & Perce \\
\hline \multicolumn{3}{|l|}{ Demography } \\
\hline Sex (Proportion of women) & 124 & 68.9 \\
\hline \multicolumn{3}{|l|}{ Age in years } \\
\hline$<20$ & 1 & 0.6 \\
\hline $20-29$ & 35 & 19.4 \\
\hline $30-39$ & 44 & 24.4 \\
\hline $40-49$ & 56 & 31.1 \\
\hline $50-59$ years & 34 & 18.9 \\
\hline$\geq 60$ years & 8 & 4.4 \\
\hline Missing & 1 & 0.6 \\
\hline \multicolumn{3}{|l|}{ Education } \\
\hline Secondary school graduation & 81 & 45.0 \\
\hline High school, University entrance qualification & 94 & 52.2 \\
\hline Other & 4 & 2.2 \\
\hline Missing & 1 & 0.6 \\
\hline \multicolumn{3}{|l|}{ Occupation } \\
\hline Physician & 19 & 10.6 \\
\hline Nurse & 100 & 55.6 \\
\hline Therapist & 7 & 3.9 \\
\hline Medical technical assistant & 8 & 4.4 \\
\hline Administrative personnel & 29 & 16.1 \\
\hline Others & 16 & 8.9 \\
\hline Missing & 1 & 0.6 \\
\hline \multicolumn{3}{|l|}{ Field of activity } \\
\hline ICU/IMC/ OP & 70 & 38.9 \\
\hline Normal ward & 54 & 30.0 \\
\hline Diagnostic & 13 & 7.2 \\
\hline Administration/ technician & 17 & 9.4 \\
\hline Others & 25 & 13.9 \\
\hline Missing & 1 & 0.8 \\
\hline \multicolumn{3}{|l|}{ Professional experience in years } \\
\hline$\leq 1$ & 12 & 6.7 \\
\hline $1-5$ & 24 & 13.3 \\
\hline $6-10$ & 24 & 13.3 \\
\hline $11-20$ & 74 & 41.1 \\
\hline $21-40$ & 41 & 22.8 \\
\hline$>41$ & 4 & 2.2 \\
\hline Missing & 1 & 0.6 \\
\hline \multicolumn{3}{|l|}{ Partnership } \\
\hline Yes & 135 & 75.0 \\
\hline No & 45 & 25.0 \\
\hline \multicolumn{3}{|l|}{ Household } \\
\hline One-person & 35 & 19.4 \\
\hline Multi-persons & 144 & 80.0 \\
\hline
\end{tabular}

Table 1 Descriptive statistics (Continued)

\begin{tabular}{|c|c|c|}
\hline & Numb & Percen \\
\hline Missing & 1 & 0.6 \\
\hline \multicolumn{3}{|c|}{ Work-related MRSA-risk factors } \\
\hline \multicolumn{3}{|c|}{ Having close contact to patients (washing, dressing changes,..) } \\
\hline Yes & 112 & 62.2 \\
\hline No & 67 & 37.2 \\
\hline Missing & 1 & 0.6 \\
\hline \multicolumn{3}{|c|}{ Having contact to MRSA-patients within the last 4 weeks } \\
\hline Yes & 53 & 29.4 \\
\hline No & 66 & 36.7 \\
\hline Unknown & 58 & 32.2 \\
\hline Missing & 3 & 1.7 \\
\hline
\end{tabular}

Wearing protective cloths when having contact to MRSA-patients

$\begin{array}{lll}\text { Yes, always } & 44 & 83.0 \\ \text { Occasionally without } & 3 & 5.7 \\ \text { Missing } & 6 & 11.3\end{array}$

What kind of protective cloths when having contact to MRSA-patients

$\begin{array}{lll}\text { Surgical face mask, disposable gloves and lab } \quad 42 & 49.2\end{array}$ coat

Surgical face mask and disposable gloves $\quad 5 \quad 9.4$

$\begin{array}{lll}\text { Surgical face mask } & 1 & 1.9\end{array}$

$\begin{array}{lll}\text { Disposable gloves } & 1 & 1.9\end{array}$

$\begin{array}{lll}\text { Not applicable } & 1 & 1.9\end{array}$

$\begin{array}{lll}\text { Missing } & 2 & 2.3\end{array}$

Working abroad

Yes (India/Kazakhstan, Spain, USA) $\quad 3 \quad 1.7$

$\begin{array}{lll}\text { No } & 164 & 91.1\end{array}$

$\begin{array}{lll}\text { Missing } & 13 & 7.2\end{array}$

Private MRSA-risk factors

Caring for relatives at home

$\begin{array}{lll}\text { Yes } & 9 & 5.0\end{array}$

$\begin{array}{lll}\text { No } & 171 & 95.0\end{array}$

Having contact to MRSA-carriers

$\begin{array}{lll}\text { Yes } & 3 & 1.7\end{array}$

$\begin{array}{lll}\text { No } & 132 & 73.3\end{array}$

Unknown $\quad 45 \quad 25.0$

Having contact to persons in need for care within the last 4 weeks

$\begin{array}{lll}\text { Yes } & 22 & 12.2 \\ & 158 & 87.8\end{array}$

$\begin{array}{lll}\text { No } & 158 & 87.8\end{array}$

Working in the ambulant sector outside work

$\begin{array}{lll}\text { Yes } & 2 & 1.1 \\ \text { No } & 178 & 98.9\end{array}$

Having contact to farm animals

$\begin{array}{lll}\text { Yes } & 9 & 5.0 \\ \text { No } & 171 & 195.0\end{array}$

Having contact to pets 
Table 1 Descriptive statistics (Continued)

\begin{tabular}{|c|c|c|}
\hline & Number & Percent \\
\hline Yes & 89 & 49.4 \\
\hline No & 89 & 49.4 \\
\hline Missing & 2 & 1.1 \\
\hline \multicolumn{3}{|l|}{ Chronic skin disease } \\
\hline Yes, own diagnosis & 4 & 2.2 \\
\hline Yes, doctor's diagnosis & 15 & 8.3 \\
\hline No & 158 & 87.8 \\
\hline Missing & 3 & 1.7 \\
\hline \multicolumn{3}{|l|}{ Chronic respiratory disease } \\
\hline Yes, own diagnosis & 7 & 3.9 \\
\hline Yes, doctor's diagnosis & 15 & 8.3 \\
\hline No & 154 & 85.6 \\
\hline Missing & 4 & 1.7 \\
\hline \multicolumn{3}{|l|}{ Diabetes mellitus } \\
\hline Yes, own diagnosis & 1 & 0.6 \\
\hline Yes, doctor's diagnosis & 3 & 1.7 \\
\hline No & 167 & 92.8 \\
\hline Missing & 9 & 5.0 \\
\hline \multicolumn{3}{|l|}{ Having had MRSA } \\
\hline Yes & 4 & 2.2 \\
\hline No & 176 & 97.8 \\
\hline \multicolumn{3}{|c|}{ Use of antibiotics within the last 12 months } \\
\hline Yes & 57 & 31.7 \\
\hline No & 121 & 67.2 \\
\hline Missing & 2 & 1.1 \\
\hline \multicolumn{3}{|c|}{ Hospital stay within the last 12 months } \\
\hline Yes & 16 & 8.9 \\
\hline No & 161 & 89.4 \\
\hline Missing & 3 & 1.7 \\
\hline
\end{tabular}

wearing protective clothing at all times. The person was also treated with antibiotics within the last 12 months. These are common risk factors for MRSA colonization in HCWs $[13,28]$. Thus, although the sample size is too low to make general assumptions about risk factors for MRSA carriage, our results fit to the body of evidence for potential risk factors [28, 29].

The isolated strain was not one of the more common nosocomial strains in Germany. The isolate was CC1-MRSA-IV which is identical to WA MRSA-1/57 from Western Australia [30-32]. This strain is very common in Romania [33] and has also been isolated in Germany, Ireland, and Saudi Arabia [32, 34-37]. CC1-MRSA-IV is a traditional community acquired MRSA strain. This may suggest that the MRSA-positive tested person may have been colonized outside the hospital. Yet, recent observations suggest the spread
CC1-MRSA-IV within and between hospitals and communities [37]. Thus, it is also possible that the acquisition of MRSA occurred within the hospital. The MRSA carrier in our study had contact to patients with MRSA within the last 4 weeks. It has been shown that work clothes, especially the gloves of $\mathrm{HCW}$, are often contaminated with multidrug resistant bacteria during routine care [38, 39]. Unfortunately, we do not have data from patient admission screenings and patient MRSA status during the study period.

The response rate was rather low (31.3\%). Sick leave, vacation and the regular distribution of working times may have prevented a certain proportion of the employees from having a chance to participate in the study. Study participation was on a voluntarily basis. Although individuals had the opportunity to participate anonymously, some may have declined participation due to a fear of adverse professional consequences, such as fear of stigmatization when tested positive for MRSA. A recent work by Peters and colleagues showed that German hospitals deal differently with MRSA-positive staff [19]. Recommendations concerning workers that are MRSA carriers range from following standard hygiene procedures to restricting MRSA-colonized workers from working with patients, or even requiring them to take time off from work. Moreover, in exceptional cases, it was reported that employees were fired from work due to permanent MRSA-colonization. Thus, the fear of stigmatization and job loss may have influenced study participation. There are recommendations for specific hygiene measures by the German Commission for Hospital Hygiene and Infection Prevention (KRINKO - Kommission für Krankenhaushygiene und Infektionsprävention) [29]. However, these recommendations concern work restrictions for MRSA positive staff during outbreaks. In non-outbreak situations, hospitals deal differently with MRSA colonized staff [19]. National regulations would be helpful for handling MRSA-colonized staff.

The major limitations of the study are the small sample size and the low response rate (149 of 575). However, participant characteristics matched general employee characteristics concerning age and sex suggesting low bias. Furthermore, we only tested staff members, and no patients were tested, making it difficult to make assumptions about the transmission paths [40]. Also, it would be useful to know whether the same MRSA strains are found in staff and patients. Another limitation is the cross-sectional study design which may have led to over- or underestimation of MRSA prevalence. Furthermore, we only obtained samples from the anterior nares. It has been shown that screening other body sites increases MRSA yield by about one third over nares alone [41]. Thus, subjects colonized with MRSA at other body 
sites (e.g. throat and axilla) may have been missed, leading to an underestimation of MRSA-prevalence.

\section{Conclusion}

The results suggest a low prevalence of MRSA in a German cardiac care center in a non-outbreak setting. The results also correspond with the emerging trend of decreasing MRSA carriage prevalence in Europe that may be due to improved hygiene measures. Nevertheless, there is still a need for national regulations for dealing with MRSA-colonized staff in the healthcare sector.

\section{Abbreviations}

HCW: Health care workers; MRSA: Methicillin Resistant Staphylococcus aureus

\section{Acknowledgements}

Special thanks to Katrin Liesk-Biskop, Franziska Kynast and Iris Bräunig for their great support with the study execution. We are grateful for the support of Prof. Enno Jacobs and Tobias Löwe from the Institute of Medical Microbiology and Hygiene, Medical Faculty Carl Gustav Carus of the Technische Universität Dresden.

\section{Funding}

This work was support by the Statutory Accident Insurance and Prevention in the Health and Welfare Services, Hamburg, Germany. We acknowledge support by the Open Access Publication Funds of the SLUB/TU Dresden.

\section{Availability of data and materials}

Data are shown in the manuscript.

\section{Authors' contributions}

AS is the originator of the study and suggested the research question. Responsible for the conduct of the study were AS, DK, MS, LJ, AS and RS. MS was responsible for study management and DK was responsible for data collection. $L, A N$ and MD provided expertise for the research question and in the field of infectious diseases. MS conducted the analyses and prepared the first draft of the manuscript which was finalized jointly by all authors. All authors read and approved the final manuscript.

\section{Ethics approval and consent to participate}

The study was approved by the ethics committee of the Technische Universität Dresden (EK 232062014). Informed consent was obtained from all participants.

\section{Consent for publication}

Not applicable.

\section{Competing interests}

The authors declare that they have no competing interests.

\section{Publisher's Note}

Springer Nature remains neutral with regard to jurisdictional claims in published maps and institutional affiliations.

\footnotetext{
Author details

${ }^{1}$ Institute and Policlinic of Occupational and Social Medicine, Medical Faculty Carl Gustav Carus, Technische Universität Dresden, Dresden, Germany. ${ }^{2}$ Department of Hospital Infection Control, Medical Faculty Carl Gustav Carus, Technische Universität Dresden, Dresden, Germany. ${ }^{3}$ Heart Center, University Hospital of the Technical University Dresden, Dresden, Germany. ${ }^{4}$ Medical Faculty Carl Gustav Carus, Technische Universität Dresden, Dresden, Germany. ${ }^{5}$ Department of Occupational Medicine, Public Health and Hazardous Substances, Institution for Statutory Accident Insurance and Prevention in the Health and Welfare Services, Hamburg, Germany. ${ }^{6}$ Competence Centre for Epidemiology and Health Services Research for Healthcare Professionals (CVcare), University Medical Centre Hamburg-Eppendorf (UKE), Hamburg, Germany.
}

Received: 12 October 2018 Accepted: 26 February 2019 Published online: 12 March 2019

\section{References}

1. European Centre for Disease Prevention and Control. Antimicrobial resistance surveillance in Europe: Surveillance report. 2015.

2. European Centre for Disease Prevention and Control.Surveillance of antimicrobial resistance in Europe: Annual report of the European antimicrobial resistance surveillance network (EARS-Net). 2017.

3. European Centre for Disease Prevention and Control. Antimicrobial resistance surveillance in Europe 2012. Annual report of the European antimicrobial resistance surveillance network (EARS-Net) Stockholm. 2013.

4. Hawkins G, Stewart S, Blatchford O, Reilly J. Should healthcare workers be screened routinely for meticillin-resistant Staphylococcus aureus? A review of the evidence. J Hosp Infect. 2011;77(4):285-9.

5. Cimolai $\mathrm{N}$. The role of healthcare personnel in the maintenance and spread of methicillin-resistant Staphylococcus aureus. J Infect Public Health. 2008;1(2):78-100.

6. Eveillard M, Martin Y, Hidri N, Boussougant Y, Joly-Guillou M-L. Carriage of methicillin-resistant Staphylococcus aureus among hospital employees: prevalence, duration, and transmission to households. Infect Control Hosp Epidemiol. 2004;25(2):114-20

7. Mollema F, Richardus JH, Behrendt M, Vaessen N, Lodder W, Hendriks W, et al. Transmission of methicillin-resistant Staphylococcus aureus to household contacts. J Clin Microbiol. 2010;48(1):202-7.

8. Ng W, Faheem A, McGeer A, Simor AE, Gelosia A, Willey BM, et al. Community-and healthcare-associated methicillin-resistant Staphylococcus aureus strains: an investigation into household transmission, risk factors, and environmental contamination. Infect Control Hosp Epidemiol. 2017;38(1):61-7.

9. Köck R, Becker K, Cookson B, van Gemert-Pijnen J, Harbarth S, Kluytmans J, et al. Methicillin-resistant Staphylococcus aureus (MRSA): burden of disease and control challenges in Europe. Euro Surveill. 2010;15(42):19694.

10. Köck R, Becker K, Cookson B, van Gemert-Pijnen J, Harbarth S, Kluytmans J, et al. Systematic literature analysis and review of targeted preventive measures to limit healthcare-associated infections by meticillin-resistant Staphylococcus aureus. Euro Surveill. 2014;19(29):20860.

11. Dulon M, Peters C, Schablon A, Nienhaus A. MRSA carriage among healthcare workers in non-outbreak settings in Europe and the United States: A systematic review. BMC Infect Dis. 2014;14:363.

12. Sassmannshausen R, Deurenberg RH, Köck R, Hendrix R, Jurke A, Rossen JW, et al. MRSA prevalence and associated risk factors among health-care workers in nonoutbreak situations in the Dutch-German EUREGIO. Front Microbiol. 2016;7:1273.

13. Ibarra M, Flatt T, Van Maele D, Ahmed A, Fergie J, Purcell K. Prevalence of methicillin-resistant Staphylococcus aureus nasal carriage in healthcare workers. Pediatr Infect Dis J. 2008;27(12):1109-11.

14. Schablon A, Kleinmüller O, Nienhaus A, Peters C. MRSA prevalence among patient transport staff in Hamburg. GMS Hyg Infect Control. 2018;13:Doc03.

15. Albrich WC, Harbarth S. Health-care workers: source, vector, or victim of MRSA? Lancet Infect Dis. 2008;8(5):289-301.

16. Brans R, Kolomanski K, Mentzel F, Vollmer U, Kaup O, John SM. Colonisation with methicillin-resistant Staphylococcus aureus and associated factors among nurses with occupational skin diseases. Occup Environ Med. 2016; 73(10):670-5

17. Cookson B, Peters B, Webster M, Phillips I, Rahman M, Noble W. Staff carriage of epidemic methicillin-resistant staphylococcus aureus. J Clin Microbiol. 1989;27(7):1471-6.

18. Haamann F, Dulon M, Nienhaus A. MRSA as an occupational disease: A case series. Int Arch Occup Environ Health. 2011;84(3):259-66.

19. Peters C, Dulon M, Lietz J, Nienhaus A. Der Umgang mit MRSA bei Beschäftigten im Gesundheitsdienst aus Sicht der Krankenhaushygiene. Das Gesundheitswesen. 2017;79(08/09):648-54.

20. Dulon M, Lisiak B, Wendeler D, Nienhaus A. Berufsbedingte Infektionskrankheiten bei Beschäftigten im Gesundheitsdienst 2014 (Occupational infectious diseases in healthcare workers 2014). Zentralbl Arbeitsmed Arbeitsschutz Ergon. 2015;65(4):210-6.

21. Peters $C$, Dulon $M$, Kleinmüller $O$, Nienhaus $A$, Schablon A. MRSA prevalence and risk factors among health personnel and residents in nursing homes in Hamburg, Germany- A cross-sectional study. PLoS One. 2017;12(1): e0169425.

22. Jovanovic BD, Levy PS. A look at the rule of three. Am Stat. 1997:51(2): 137-9. 
23. Kaminski A, Kammler J, Wick M, Muhr G, Kutscha-Lissberg F. Transmission of methicillin-resistant Staphylococcus aureus among hospital staff in a German trauma Centre: A problem without a current solution? Bone Joint J. 2007:89(5):642-5.

24. Joos AK. MRSA-Personalscreening in einer Chirurgischen Universitätsklinik. Hyg Med. 2009;34:183-7.

25. Witte W, Mielke M, Ammon A, Nassauer A, Wischnewski N, Fachtagung d AG. Nosokomiale Infektionen am RKI zur Intensivierung der Umsetzung von Präventionsstrategien bei MRSA. Epidemiol Bull. 2005;5:31-8.

26. Sächsische Staatskanzlei. Verordnung der Sächsischen Staatsregierung über die Hygiene und Infektionsprävention in medizinischen Einrichtungen vom 12. Juni 2012 (SächsGVBI. S. 320); 2012.

27. Allegranzi B, Pittet D. Role of hand hygiene in healthcare-associated infection prevention. J Hosp Infect. 2009;73(4):305-15.

28. Lekkerkerk W. Haenen A, van der Sande M, Leenstra T, de Greeff S, Timen A, et al. Newly identified risk factors for MRSA carriage in the Netherlands. PLoS One. 2017;12(11):e0188502.

29. Ruscher C. Empfehlungen zur Prävention und Kontrolle von Methicillinresistenten Staphylococcus aureus-Stämmen (MRSA) in medizinischen und pflegerischen Einrichtungen. Bundesgesundheitsbl Gesundheitsforsch Gesundheitsschutz. 2014;57(6):695-732.

30. Coombs GW, Monecke S, Pearson JC, H-I T, Chew Y-K, Wilson L, et al. Evolution and diversity of community-associated methicillin-resistant Staphylococcus aureus in a geographical region. BMC Microbiol. 2011;11(1):215.

31. O'brien F, Lim T, Chong F, Coombs G, Enright M, Robinson D, et al. Diversity among community isolates of methicillin-resistant Staphylococcus aureus in Australia. J Clin Microbiol. 2004;42(7):3185-90.

32. Monecke S, Coombs G, Shore AC, Coleman DC, Akpaka P, Borg M, et al. A field guide to pandemic, epidemic and sporadic clones of methicillinresistant Staphylococcus aureus. PLoS One. 2011;6(4):e17936.

33. Monecke $S$, Müller E, Dorneanu OS, Vremeră T, Ehricht R. Molecular typing of MRSA and of clinical Staphylococcus aureus isolates from laşi, Romania. PLoS One. 2014;9(5):e97833.

34. Albrecht N, Jatzwauk L, Slickers P, Ehricht R, Monecke S. Clonal replacement of epidemic methicillin-resistant Staphylococcus aureus strains in a German university hospital over a period of eleven years. PLoS One. 2011;6(11): e28189.

35. Shore AC, Tecklenborg SC, Brennan GI, Ehricht R, Monecke S, Coleman DC. Panton-valentine leukocidin-positive Staphylococcus aureus in Ireland from 2002 to 2011: 21 clones, frequent importation of clones, temporal shifts of predominant methicillin-resistant $\mathrm{S}$. aureus clones, and increasing multiresistance. J Clin Microbiol. 2014;52(3):859-70.

36. Senok A, Ehricht R, Monecke S, Al-Saedan R, Somily A. Molecular characterization of methicillin-resistant Staphylococcus aureus in nosocomial infections in a tertiary-care facility: emergence of new clonal complexes in Saudi Arabia. New Microbes New Infect. 2016;14:13-8.

37. Earls MR, Kinnevey PM, Brennan Gl, Lazaris A, Skally M, O'Connell B, et al. The recent emergence in hospitals of multidrug-resistant communityassociated sequence type 1 and spa type t127 methicillin-resistant Staphylococcus aureus investigated by whole-genome sequencing: implications for screening. PLoS One. 2017;12(4):e0175542.

38. Morgan DJ, Rogawski E, Thom KA, Johnson JK, Perencevich EN, Shardell M, et al. Transfer of multidrug-resistant bacteria to healthcare workers' gloves and gowns after patient contact increases with environmental contamination. Crit Care Med. 2012;40(4):1045.

39. Pineles L, Morgan DJ, Lydecker A, Johnson JK, Sorkin JD, Langenberg P, et al. Transmission of methicillin-resistant Staphylococcus aureus to health care worker gowns and gloves during care of residents in veterans affairs nursing homes. Am J Infect Control. 2017:45(9):947-53.

40. Price JR, Cole K, Bexley A, Kostiou V, Eyre DW, Golubchik T, et al. Transmission of Staphylococcus aureus between health-care workers, the environment, and patients in an intensive care unit: a longitudinal cohort study based on whole-genome sequencing. Lancet Infect Dis. 2017;17(2): 207-14.

41. McKinnell JA, Huang SS, Eells SJ, Cui E, Miller LG. Quantifying the impact of extra-nasal testing body sites for MRSA colonization at the time of hospital or intensive care unit admission. Infect Control Hosp Epidemiol. 2013;34(2):161.

\section{Ready to submit your research? Choose BMC and benefit from}

- fast, convenient online submission

- thorough peer review by experienced researchers in your field

- rapid publication on acceptance

- support for research data, including large and complex data types

- gold Open Access which fosters wider collaboration and increased citations

- maximum visibility for your research: over $100 \mathrm{M}$ website views per year

At BMC, research is always in progress.

Learn more biomedcentral.com/submissions 